\title{
Lipovetsky, Gilles e Serroy, JeAn (2014). O capitalismo ESTÉTICO NA ERA DA GLOBALIZAÇÃO, LISBOA: EDIÇÕES 70
}

\author{
Esser Silva
}

Dando forma à sua notoriedade camaleónica capaz de se metamorfosear e de modificar as sociedades através de trajetos históricos silenciosos, processos indeléveis e objetivos precisos, o capitalismo segue a sua natureza, apropriando-se do outrora autónomo mundo das artes, então regido pela independência e regras específicas dos artistas, possuidores de instâncias de controlo, formas e códigos próprios de escolha e seleção. A incompatibilidade original entre o campo artístico e o capitalismo entra numa fase em que as sociedades se vêm gradualmente transformadas na consagração de um mundo "artealizado" observado em várias dimensões, desde a moda à arquitetura, do cinema ao centro comercial e expresso em misturas de mau gosto e mudanças aceleradas.

Os autores refletem sobre a existência de uma sociedade com um modo de produção baseado no hibridismo, prazer constante, sedução e novidade, empreendedora de uma economia artística empobrecida e desligada da cultura erudita que atinge o seu apogeu na "época hipermoderna", sendo esta caracterizada por um "capitalismo transestético" à escala global.

Gilles Lipovetsky é professor de Filosofia na Universidade de Grenoble. Desde "A Era do Vazio - Ensaio do individualismo contemporâneo", publicado em 1983, inicia uma reflexão construída a partir de um campo metodológico de análise do século XX através da exploração do processo histórico da sociedade ocidental, concentrando o olhar na transição entre a sociedade industrial e a sociedade pós-industrial.

Jean Serroy, também professor na Universidade de Grenoble, é autor de várias obras sobre cinema e literatura do século XVIII. Conjuntamente com Lipovetsky publicou "O Ecrã-Global" (2007), uma abordagem compreensiva da proliferação e dos impactos dos ecrãs nas sociedades e "A Cultura-Mundo" (2010) obra que explora os conceitos de mundialização da cultura, indústria cultural hipermoderna e tecnociência na sociedade contemporânea.

Nesta obra os autores descortinam alterações comportamentais conducentes ao fenómeno da individualidade, afirmando a presença de uma sociedade pós-moderna. Para Lipovetsky o culto do novo e da moda como dispositivo social personificado num consumidor ávido, em constante procura de sedução, dá lugar a um estilo de vida hedonista, esteta e lúdico, transformando os indivíduos e desestruturando-os das ideias utópicas revolucionárias que haviam ocupado a modernidade.

O tema é introduzido ao leitor a partir do enunciado do processo evolutivo do campo artístico constituído como um problema. Essa trajetória pode dividir-se em quatro 
fases. Inicia-se na «artealização ritual» onde há arte mas ainda não existe artista. Segue-se a «estetização aristocrática», herdeira da Antiguidade Clássica, presente entre a época renascentista e o final do século XVIII que entrevê a noção de imperfeição e o poder criador. A assinatura separa o artista do artesão com os valores estéticos a adquirirem "uma dignidade, uma importância social novos" (p. 23).

A partir da "estetização moderna do mundo", cuja plenitude se dá na Idade Moderna, entre os séculos XVIII e XIX, a arte liberta-se de todos os outros poderes impondo a sua autonomia, "as suas leis, valores, e os seus próprios princípios de legitimidade" através das instâncias próprias de "seleção e consagração" (p. 24). Distingue-se aqui a "arte propriamente dita", vanguardista, independente, orgulhosa em si e desprendida, da "arte comercial", constituída para o mundo económico, orientada para o "lucro, (...) sucesso imediato e temporária (...), ajustada às exigências do público” (p. 25). As duas formulações opõem radicalmente dois modos contraditórios de produção manifestos entre "arte e comercial, cultura e indústria, puro e impuro, autêntico e kitsch, arte de elite e cultura de massas" (p. 25). A modernidade introduz a "estetização radical da arte pura" (p. 30) ao mesmo tempo que dá vida a um "processo de desestetização" (p. 29) com claros reflexos na arquitetura e urbanismo.

Confronta-se, a partir daqui, uma produção artística de luxo de "alto valor criativo" com uma arte de "produção industrial em série" destinada às massas (p. 30) que confluiu na "idade transestética", período em que "as vanguardas são integradas na ordem económica" (p. 31). Findam-se as grandes oposições e passa a prevalecer a multiplicação de soluções criativas dominadas pela emoção onde o importante "é sentir, viver os momentos de prazer, de descoberta ou de evasão" (p. 35) em que se promove uma sociedade cuja afirmação identitária é a diferenciação, emergindo daí um indivíduo com tanto de consumista como de inconformista, "obcecado com o descartável" (p. 36) e com a beleza mutável.

A ideia de um capitalismo absorvendo as artes através da introdução de traços de representação cinematográfica, convoca no imediato a dramaturgia goffmaniana em que os indivíduos agem em obediência à representação de um papel, no qual a personagem sabe constar, através da interpretação, os signos e os rituais distinguidos e reconhecidos por outros indivíduos ou grupos, por forma a obter o melhor resultado do seu desempenho. Todavia, em Goffman, os atores são livres de entrarem e saírem de cena. Nesta obra, os seis capítulos que corporizam o livro perscrutam uma noção dramatúrgica naturalizada e com propriedades holísticas, onde o capitalismo artestético envolve a totalidade existencial sem que os indivíduos se apercebam sob um manto de poder.

O primeiro capítulo da obra explana e desconstrói a perspetiva fordista-taylorista e que veicula a "noção de aliança entre capitalismo e arte" para o entendimento tradicional do capitalismo artístico. Presente na moda aceleradamente efémera, no gigantismo da arquitetura fria, na massificação e na cópia como modelo na explosão dos lugares da arte e dominada pelo mau gosto, o capitalismo artístico serve-se da "flexibilidade contratual" e "dos empregos atípicos" promovendo a "individualização e a multiplicação das formas" (p. 72) que reconfigura, ao mesmo tempo, a esfera do lazer, da cultura e da própria arte. 
A formação de um todo integrado a partir (i) do estilo, da sedução e da emoção (ii) da generalização da dimensão empresarial das indústrias criativas como um mundo distinto (iii) de "grupos comprometidos nas produções dotadas de uma componente estética" e (iv) a desestabilização das "antigas hierarquias artísticas e culturais", promovem uma nova reinterpretação que passam a funcionar segundo "processos de hibridação" resultantes de misturas de tudo o que antes era separado e dividido (pp. 49-53). A lógica acelerada e hiperbolizada, heterogeneizada numa "diversificação prolífica" a partir do "capital dito imaterial", ultrapassam a noção pós-modernista de uma "sociedade de conhecimento" avançando para uma nova fase do capitalismo onde prevalece "a inteligência" baseada nos pressupostos da "inovação criativa" traduzidos na "imaginação", posse de "qualidades expressivas e cooperativas, de "competências emocionais" e "o conjunto dos saberes humanos, incluindo os intuitivos" (p. 49).

No segundo capítulo enunciam-se as condições gerais que dão origem ao capitalismo artístico, surgido a partir da economia liberal. Após a Segunda Guerra Mundial, a esfera económica autonomiza-se, as mercadorias passam a comunicar e dá-se o florescimento dos grandes armazéns, do design, da alta-costura, da embalagem, publicidade, cinema, indústria musical, promotores da "revolução da produção de massas". Nesta voragem aglutinadora, passa-se de um capitalismo estendido para o triunfo da dimensão transestética (p. 155) em que, para além dos entrecruzamentos, o regime amplia-se passando a funcionar segundo os cânones de "maior, híper e planetário".

A mudança de escala e a arquitetura multiplicam os grandes espaços estéticos, locais onde "tudo é ao contrário como se estivesse esterilizado" (p. 221), desde a localização, "à climatização, à iluminação artificial" (p. 221) onde se dá "o comércio em espetáculo faraónico" não faltando as "catedrais de consumo" (p. 168) dominadas pela "lógica da sedução estética" (p.171) da qual não escapa nem a moda nem a alta-costura, incapazes de se separarem "da espetacularização, da encenação feérica das criações comerciais" (p. 175). O princípio da cópia ganha relevo e o original, tal como já havia previsto Walter Benjamim, desaparece na floresta de reproduções. O princípio passa a aplicar-se ao cinema que absorve e anula os direitos de muitos escritores através de uma produção estandardizada baseada no "entertainment que funciona de facto como a moda com os seus modelos constantemente cambiáveis " (p. 233).

Os novos usos do design e as explicações dos seus câmbios até se tornar numa peça fundamental da engrenagem do capitalismo artístico ocupam o terceiro capítulo. Tal como outras noções subsumidas na economia, também o design está em todos os continentes e em todo o lado, seja no "decorativo" ou no "subjetivo expressivo" (p. 263) numa renovação do conceito à escala mundial. A mistura de géneros e a reutilização produzem um novo universo onde prevalece o kitsch como resultado da "cultura da hibridação". Com as fronteiras alargadas, afirmar-se um "tipo de design feito de sobreposições, de interpenetrações, de transversalidades" (p. 280). O modo de produção taylorista-fordiana é invadido pela obrigação de conceber variedades, aumentando o ritmo de lançamento.

O mercado das massas dá lugar aos "micromercados" e "necessidades cada vez mais diferenciadas" (p. 265) e personalizados, num processo de contante e acelerada 
renovação da oferta que troca o vanguardismo pelo retro. Mesmo as novas temáticas surgidas dos excursos ambientalistas se vêm invadidas pela ideia de design sustentável (p. 298) que, simultaneamente, contestam o "produtivismo" destruidor da biosfera e, ao mesmo tempo, promovem uma intensa profusão de novos produtos amigos do ambiente que tomam conta da vida quotidiana.

A transformação que opõe a "sociedade do espetáculo" descrita por Guy Debord e a "era do hiperespetáculo" (p. 301), através da mutação associada ao florescimento das "indústrias criativas" - nova designação dada à crítica das "indústrias culturais" da Escola de Frankfurt - ocupa o quarto capítulo. A nova sociedade é atravessada por oito eixos: i) a sociedade da televisão de espetáculo incipiente é substituída pela sociedade dos ecrãs, caracterizada pela "superabundância mediática" e geradora de um "hipertelespetador, interativo e permanente" (p. 305); ii) sem as restrições do espaço e do tempo produzem-se grandes alterações nos modos de consumo, desritualizando a prática coletiva e promovendo o consumo individualizado em que o espertador se torna num "programador autónomo" (p. 305); iii) a separação, condição supra da sociedade do espetáculo, dá lugar à "desdiferenciação" (p. 306), à mistura, a entrelaçamentos e à transversalidade; iv) o público adota a postura dos atores e, afinal, ao contrário do imaginado pela Escola de Frankfurt, os indivíduos não se tornam em seres passivos e manipulados mas em manipuladores do mundo do espetáculo; v) este, o espetáculo, não decorre do engano, não serve para impressionar, nem para promover fugas mentais do quotidiano ajudando à sobrevivência através da ilusão, mas para gerar "experiencia vivida" e uma "economia de experiência" (p. 307) aumentando a realidade e hiperbolizando a existência; vi) tudo se tornou imenso, numa lógica "hipertrófica da melhor oferta" onde o choque, o brilho, a transgressão, a surpresa do impensável realizado, funcionam segundo uma "lógica hiperlativa" (p. 309) na qual prevalece a ausência de limites; vii) a vedetização, antes território das estrelas, abrange hoje todos os grupos e as áreas da sociedade. Universalizou-se a "economia do estrelato" (p. 309) e o star system atravessa toda a cultura; viii) desaparecem as encenações clássicas histórico-religiosas que engrandeciam os deuses substituídas pelo "divertimento turístico, o sonho, o prazer imediato" no qual a "excrescência de meios (...) promove uma sociedade comercial de alegria de massas" (p. 310).

O capitalismo transestético apresenta sempre uma novidade escondida na manga para surpreender e saciar a predisposição do indivíduo para o desconhecido aparentemente inimaginável. Seja através do choque, do gigantismo, da provocação a realidade torna-se num show de celebridades produzindo um "espetáculo dentro do espetáculo" (p. 321) onde o sensacional e o abjeto conseguem coexistir ao mesmo nível na "experiência divertida do diferente" (p. 325) em que o kitsch se pluraliza e se impulsiona desavergonhadamente, exibindo-se através do individualismo em que cada um se dedica a construir-se e a inventar-se permanentemente.

Os autores servem-se do capítulo cinco para dissertar sobre a ocupação das cidades pelo capitalismo estético introduzindo-Ihes o traço e a ambiência da "cidade shopping" ou "cidade-lazer" e os novos hábitos de consumo cultural entretanto surgidos. Enquanto 
as áreas pedonais do shopping inspiram-se nas ruas, as cidade recriam a sinalética, as vitrinas, as montras dos centros comerciais e "edifícios-marca espalham a sua identidade visual" numa recriação da paisagem urbana centrada na "requalificação e estetização" (p. 367) num contexto de intensa concorrência entre cidades para ganhar em atração, como se o espaço passasse, ele também, por um permanente concurso de beleza.

Ao contrário da cidade industrial, a cidade hipermoderna já não glorifica o trabalho material. A metamorfose radica-se no prazer, entretenimento e diversão a partir de atividades não produtivas baseadas no "imaterial", no "lúdico" e no "cultural". O património histórico desintegra a sociedade de bairro, servindo-se do cenário para promover um comércio retraduzido, dando-se o incremento e "expansão do consumo estetizado" (p. 379) onde nasce e se afirma o homo aestheticus. Dominado pela sociedade transestética, centrada em buscas do prazer e da emoção, esta nova figuração do indivíduo resulta da "desformalização cultural" (p.389), estando longe da estética da sociedade da corte fundada em "normas sociais estritas (...) que davam lugar à teatralidade, à decoração, ao parecer social" (p. 389) na sociedade de palácio configurada por Norbert Elias.

A época hipermoderna contempla variantes do homo aestheticus e, tanto homo festivus como o homo consumans, concebem-se dominados pela beleza ideal da magreza e do corpo longilíneo. O "eu" domina em várias vertentes, seja na moda, seja nas formas do corpo, seja nos looks individualizados, desenvolvendo-se "um novo tipo de autorretrato" (p. 431) liberto de convenções, profusamente distribuído, partilhado e comentado numa invocação permanente do instante.

Até onde irá a sociedade transestética? Esta é a questão que atravessa o sexto e último capítulo do livro. As origens do capitalismo transestético coincidem com o fim da moral ascética segundo a noção weberiana do capitalismo na modernidade, sendo a estética hedonista resultado dos "combates conduzidos pela contracultura romântica dos anos sessenta" do século XX que lutaram coletivamente contra os traços do capitalismo económico de então centrado na "alienação e o conformismo da vida burguesa" (p. 448) constituindo-se, a partir daí, uma "civilização liberal geral" que promoveu a emancipação da esfera cultural, libertando-a dos costumes arreigados.

Com o desenvolvimento de uma cultura assente na experiência, no prazer e na realização individual, explanou-se, nesta viagem, um outro conceito weberiano: o «paradoxo das consequências". A vida estética sucede a vida religiosa, um dado que marca a «destradicionalização» (p. 449) em favor da «experencialização» como "valor supremo de um estilo de vida" liberto da obrigação de adesão a qualquer norma. Na lógica hipermoderna é destruída a "conceção puritana do mundo" caracterizadora do capitalismo industrial "regido por princípios antinómicos" (p. 452) entre economia e cultura.

Os autores evitam deixar qualquer rasto que possa levar a sua tese para o entendimento do capitalismo transestético como o fim da história ou como campo maniqueísta de confronto entre o bem e o mal. Apesar da sua via individualista, a ética estética não significa um "ideal hegemónico" que encerra os indivíduos em si, "condenando-os a um niilismo exponencial" (p. 477). Persiste a necessidade de obrigações morais abrigadas nos sentimentos individuais, na medida em que é necessário fazer com que a 
sociedade transestética "evolua no sentido do nobre e do melhor para deter a febre do sempre mais" (p. 486). O individualismo triunfante não pode ser confundido com "o grau zero dos valores" (p. 477). A humanidade insiste nos seus princípios através de protestos, contribuições para causas, gestos solidários, "a indignação perante a miséria" e os "ideais de solidariedade e de entreajuda" (pp. 475-477). Por meio de movimentos porfiam-se as resistências ao mundo acelerado e permanece a crítica à maximização do consumo. O capitalismo artístico inscreve-se na "aventura da humanidade" (p. 485) à procura da melhor existência e da beleza da vida.

Estamos perante um livro profusamente ilustrado de exemplos articulados entre teorias e ensaios filosóficos, estatísticas sociológicas, verificações empíricas e resultados de experimentos do campo da psicologia social, trianguladas em pertinentes reflexões e diversificadas interpretações teóricas servidas como comprovativos, numa profusa e avassaladora torrente reflexiva, promotora de configurações de desígnio sócio-histórico, servidas ao leitor segundo uma nova visão interpretativa da sociedade hipermoderna. Lipovetsky é um autor que recorre ao enunciado paradoxal sistemático para colocar as temáticas analisadas num campo ontológico do devir, apresentando os indivíduos como seres essenciais com propriedades mutáveis tanto interior como exterior.

O individualismo hedonista, prazeroso, presenteísta, intensamente ligado ao instante mas efémero, tendo como definição o indefinido, domina a cultura mundo, expressando-se na intensidade e aceleração na mudança em permanência. As emoções e a busca de sensações, a vida sem constrangimentos, subsituem os tempos da obediência, na realização possível, da submissão à ordem estratificada. A fusão do antes imisturável, resultante no hibridismo como idiossincrasia das sociedades hipermodernas, estende-se também à profusão de técnicas, métodos e escolas convocadas pela narrativa, dando lugar a uma obra matizada, arquitetada num complexo construído a partir de diversidades.

\section{NOTA BIOGRÁFICA}

Esser Silva é doutorando do Programa Doutoral da Fundação para a Ciência e Tecnologia "Estudos de Comunicação: Tecnologia, Cultura e Sociedade" coordenado pelo Centro de Estudos Comunicação e Sociedade, Centro de Investigação e Estudos de Sociologia, Laboratório de Comunicação Online, Centro de Investigação Média e Jornalismo e Centro de Investigação em Comunicação Aplicada, Cultura e Novas Tecnologia. Projeto FCT PD/BD/52617/2014.

E-mail: esser.jorge@gmail.com

Instituto de Ciências Sociais, Universidade do Minho, Gualtar - 4710-057 Braga, Portugal

* Submetido: 09-04-2015

* Aceite: 02-07-2015 